
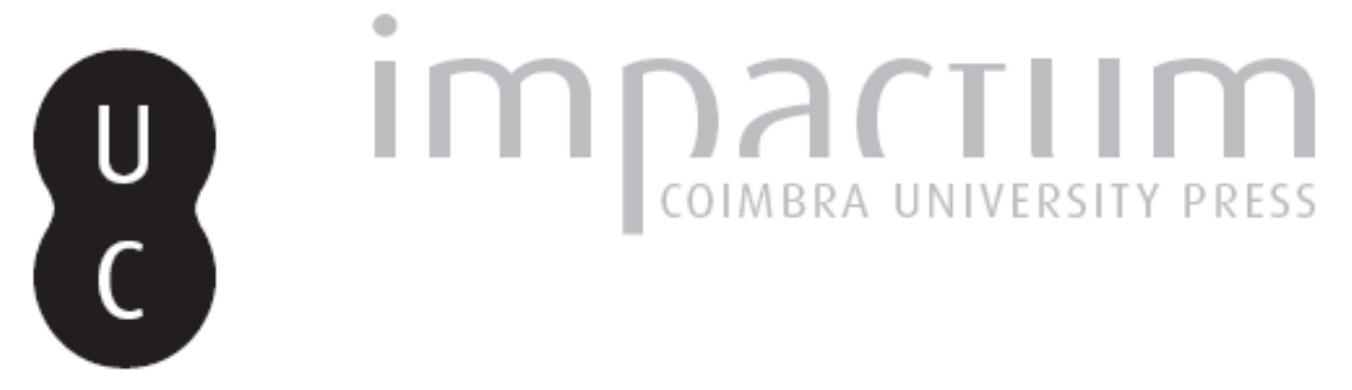

Serviço público e regiões: reflexões em torno da informação de âmbito regional

Autor(es): $\quad$ Ascensão, Patrícia

Publicado por: Imprensa da Universidade de Coimbra

URL persistente:

URI:http://hdl.handle.net/10316.2/43225

DOI:

DOI:https://doi.org/10.14195/2183-5462_31_3

Accessed : $\quad$ 26-Apr-2023 16:16:41

A navegação consulta e descarregamento dos títulos inseridos nas Bibliotecas Digitais UC Digitalis, UC Pombalina e UC Impactum, pressupõem a aceitação plena e sem reservas dos Termos e Condições de Uso destas Bibliotecas Digitais, disponíveis em https://digitalis.uc.pt/pt-pt/termos.

Conforme exposto nos referidos Termos e Condições de Uso, o descarregamento de títulos de acesso restrito requer uma licença válida de autorização devendo o utilizador aceder ao(s) documento(s) a partir de um endereço de IP da instituição detentora da supramencionada licença.

Ao utilizador é apenas permitido o descarregamento para uso pessoal, pelo que o emprego do(s) título(s) descarregado(s) para outro fim, designadamente comercial, carece de autorização do respetivo autor ou editor da obra.

Na medida em que todas as obras da UC Digitalis se encontram protegidas pelo Código do Direito de Autor e Direitos Conexos e demais legislação aplicável, toda a cópia, parcial ou total, deste documento, nos casos em que é legalmente admitida, deverá conter ou fazer-se acompanhar por este aviso. 


\section{Media Jornalismo}

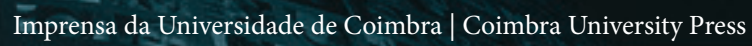

N. 31 Vol. 17, N. ${ }^{\circ} 2$ - 2017

Esia

(2) M MEDIA E DIVERSIDADE

लिखिएक

2)

*).

() (6) $3(9)$

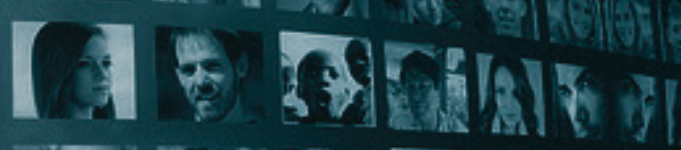

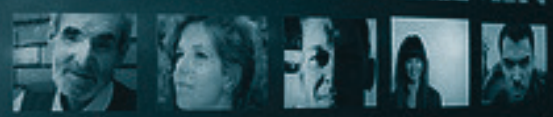

* a

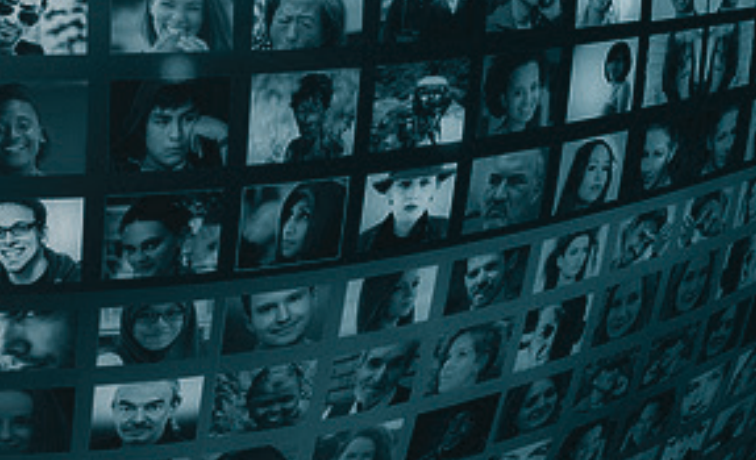

तथ 


\title{
SERVIÇO PÚBLICO E REGIÕES: REFLEXÕES EM TORNO DA INFORMAÇÃO DE ÂMBITO REGIONAL ${ }^{\mathrm{I}}$
}

\author{
REFLECTIONS ON PUBLIC SERVICE BROADCASTING AND \\ REGIONAL INFORMATION
}

PATRÍCIA ASCENSÃO

Doutoranda na Faculdade de Ciências Sociais e Humanas da Universidade Nova de Lisboa.

Centro de Investigação em Comunicação, Informação e Cultura digital

(CIC. Digital FCSh/NOVA), 1069-061 Lisboa, Portugal

patriciascensao@gmail.com

\section{Resumo}

A reflexão sobre o serviço público de rádio e de televisão insere-se num campo de discussão muito mais extenso e que se inter-relaciona com outros domínios e contextos da sociedade contemporânea. São vários os autores que consideram que o serviço público está em crise e que é crucial encontrar soluções que possam contrariar este cenário, fortemente influenciado pelas leis do mercado bem como pelas políticas definidas para o setor dos media, quer a nível nacional quer a nível europeu. Daí que seja de crucial importância continuar a investigar e a aprofundar o conhecimento sobre esta temática.

0 serviço público encerra em si responsabilidades sociais, assentes em princípios e valores que the são exigidos e que são o fundamento da sua essência e a sustentação da sua existência. A cobertura das diferentes regiões nacionais é uma das suas obrigações, especialmente num país que se caracteriza por acentuadas assimetrias regionais de ordem diversa e evidentes em quase todos os domínios da vida pública.

Este artigo, que integra uma investigação mais abrangente e cujo principal objetivo é a caracterização da informação diária de âmbito regional difundida nos principais canais da televisão e rádio públicas nacionais, procura refletir sobre a relação que existe entre regiões e serviço público, bem como o papel deste último em matérias de diversidade, pluralismo e proximidade.

\section{Palavras-chave:}

Serviço Público; Regiões; Informação; Diversidade; Proximidade

\section{Abstract}

The reflection on public service broadcasting is part of a much more extensive discussion which is related with other domains and contexts of our society. Many authors consider that public service is in crisis and it is crucial to find solutions that

I Apoiado pela FCT - Fundação para a Ciência e a Tecnologia, ao abrigo do financiamento comparticipado pelo Fundo Social Europeu e por fundos nacionais do MCTES. 
can counteract this scenario, strongly influenced by market laws as well as the media policies, both at nacional and european level. It is therefore very important to continue the research and deepen knowledge on this topic.

The public service has social responsabilities, based on basic principles and values, which are central in its mission and suport its existence. The coverage of diferent regions is one of its obligations, especially in Portugal, where we can watch proeminent regional disparities in almost all areas of social life.

This paper, which is part of a research whose main purpose is the characterization of the daily regional information which is widespread in the main portuguese public televison and radio channels, seeks to discuss the relation between regional information and public service, as well as the role of the latter with regard to diversity, pluralism and proximity.

\section{KEYWORDS:}

Public Service; Regions; News; Diversity; Proximity

\section{INTRODUÇão}

A importância do jornalismo para a sociedade tem como ideia central o papel que as notícias desempenham na estruturação da vida das pessoas. As notícias são relevantes do ponto de vista social porque emanam da realidade social, participam dela e contribuem para a construção de imagens dessa mesma realidade. São as notícias que nos aproximam do mundo em que vivemos e nos aproximam do Outro. Os meios de comunicação alargam e estruturam o nosso conhecimento do mundo, definindo aquilo que é merecedor de visibilidade e relevância social.

Neste contexto, o serviço público desempenha um papel determinante porque encerra em si valores e princípios que não devem nem podem ser esquecidos por quem contribui para a definição daquilo que é relevante em termos informativos e, consequentemente, tema de discussão no espaço público.

0 debate sobre esta matéria deu origem a inúmeros estudos, contudo, continua a ser um tema bastante pertinente pois são vários os autores que consideram que o serviço público está em crise e que é crucial encontrar soluções que possam contrariar este cenário, fortemente influenciado pelas leis do Mercado, bem como pelas políticas definidas para o setor dos media, quer a nível nacional quer a nível europeu. Desta forma, consideramos ser de grande importância repensar o serviço público de media e é também através da análise das suas práticas que esse caminho se pode trilhar.

Num mundo altamente marcado pela globalização mas onde um novo conceito de "localidade" vai ganhando terreno e novas territorialidades vão sendo construídas, 0 serviço público tem de estar à altura destas mudanças por forma a cumprir 0 seu papel relativamente à diversidade, à pluralidade e representatividade dos diferentes cidadãos, independentemente do local onde vivam.

É por esse motivo que nos interessa estudar em particular a dimensão informativa do serviço público de raádio e televisão, enquanto um dos seus eixos estruturantes, e a sua relação com o desenvolvimento regional, através da programação informativa que difunde.

Apesar dos avanços dos novos media, não podemos esquecer que a rádio e a televisão, continuam a ser os mais poderosos meios de comunicação de massas que, de 
forma gratuita, contribuem para o conhecimento da realidade. 0 consumo televisivo e radiofónico constitui ainda uma prática cultural quotidiana consistente e é a informação, entendida como prioritária, que encabeça a lista de interesses por parte dos públicos.

A estratégia definida para a programação de carácter informativo da RTP, vista por vezes como incapaz de se distinguir dos restantes operadores privados, deve assentar naquilo que é a missão do serviço público e respetivos valores, dando resposta ao que está preconizado no contrato de concessão do serviço público de rádio e televisão. Uma programação diversificada do ponto de vista regional, social e cultural, capaz de integrar de igual forma todos os cidadãos, com transparência e neutralidade, sem estar condicionada pela ditadura das audiências e do mercado, é uma obrigação fundamental do serviço público.

Este artigo integra uma investigação mais abrangente que tem, como principal objetivo, a caracterização da informação diária de âmbito regional difundida nos principais canais da televisão e rádio públicas nacionais, nomeadamente na RTP 1 e na Antena 1. A mesma procura responder à seguinte questão: considerando o papel do serviço público, como se caracteriza a informação de âmbito regional difundida no serviço público nacional de rádio e televisão e em que medida ela contribui para a promoção da pluralidade e diversidade nos meios de comunicação?

Queremos perceber como é que as regiões são representadas no serviço público de rádio e televisão no que respeita à programação informativa que é difundida. Estará o serviço público de rádio e televisão a cumprir o seu papel, em matéria de promoção da pluralidade e diversidade cultural do nosso país? Que discursos são veiculados a partir dos conteúdos informativos dedicados às realidades de âmbito regional e local? Quais os temas/assuntos predominantes nos espaços informativos do serviço público de rádio e televisão relativamente às regiões e de que forma esses assuntos são relevantes no contexto da realidade socio-económica dessa região? Qual o contributo do serviço público de rádio e televisão para a colocação e discussão no espaço público de assuntos estruturantes no âmbito do desenvolvimento regional e promoção da equidade entre regiões? Quais as fontes de informação privilegiadas e quais os protagonistas que têm voz no espaço público quando se trata de informação de âmbito regional? Qual a posição dos responsáveis editoriais e jornalistas face à informação regional e ao designado jornalismo de proximidade? Terão, eles próprios, como princípios, questões como a diversidade, a pluralidade ou a descentralização da informação no desempenho das suas funções?

Consideramos que a informação jornalística pode e deve contribuir para o desenvolvimento regional e a sua estratégia deve passar por uma informação de proximidade, virada para os reais problemas das pessoas e da comunidade. Para tal, interessa-nos analisar o que é que o serviço público está a fazer, por sua iniciativa, para promover o debate e a discussão sobre questões estratégicas para a vida das pessoas nas diferentes regiões do país, para além daquilo que é a "espuma dos dias".

\section{AS REGIÕES NO CONTEXTO DO SISTEMA AUDIOVISUAL EUROPEU}

A região é uma instância territorial que transcende o espaço físico propriamente dito, isto é, como refere Ramirez (apud Coelho, 2005: 153), ela é uma realidade que se constrói, permanentemente, através da relação humana que se estabelece entre indivíduos que partilham uma determinada identidade cultural. 
Neste processo de construção social, a comunicação funciona como elemento central na interação e relação entre os diferentes agentes sociais, seja ela mediatizada ou não. Contudo, os meios de comunicação têm um importante papel neste domínio pois contribuem para esse sentimento de identificação e pertença através dos conteúdos que difundem.

0 contexto europeu atual, por força do fenómeno da globalização, tem vindo a atribuir um peso maior à dimensão regional e local e 0 sistema audiovisual não é exceção. Um estudo de Moragas Spà et al. (1999) demonstrou que em todos os países analisados, os sistemas audiovisuais regionais e locais têm vindo a surgir e, até, a consolidar-se, num processo de descentralização em termos de políticas no setor audiovisual. Na base destas transformações estarão fatores como as reformas institucionais nos próprios países que consolidaram níveis regionais de governo (Espanha, França, Itália ou Reino Unido), o ressurgimento europeu das chamadas culturas e línguas minoritárias ou questões económicas relacionadas com a descentralização do próprio processo de produção. Para além destes fatores, salientamos ainda a fragilidade crescente do Estado-Nação tradicional, fortemente centralizado, onde a região assume um papel complementar e constitui uma resposta aos desafios colocados por uma realidade cada vez mais heterogénea e plural.

Os últimos anos foram marcados por múltiplas transformações no que respeita ao setor audiovisual e novas realidades impõem novas estratégias. Uma dessas estratégias pode passar por uma efetiva descentralização audiovisual, onde se faça uma reflexão sobre os conceitos de espaço de comunicação e de serviço de proximidade. Onde se entendam os meios de comunicação como ferramentas de reforço das identidades regionais e de promoção do desenvolvimento da própria região, cumprindo a função social com que estão comprometidos.

0 processo de descentralização da televisão na Europa tem início, ainda que de forma bastante reduzida, em meados da década de 50 com a criação da ITV (Reino Unido), uma rede de estações regionais, e da ARD (Alemanha), uma televisão pública com base em estações regionais autónomas. Contudo, apenas nos finais da década seguinte é que podemos afirmar que houve ações efetivas de descentralização levadas a cabo por algumas televisões públicas europeias, nomeadamente no Reino Unido (BBC), em França (RTF - ORTF) e em Espanha (TVE), pioneiras neste processo. Foram criados novos canais, com conteúdos de cariz regional e local, que tinham as suas próprias estruturas de produção nas principais cidades e regiões do território.

Os finais dos anos 70 e até meados dos anos 80 , foram marcados pela crescente e generalizada crítica ao monopólio da televisão pública e pelo surgimento das primeiras televisões locais. É também neste período que são criados os terceiros canais com base e conteúdos regionais, nomeadamente em França (FR3) e em Itália (RAl3).

A discussão e as reformas no setor audiovisual intensificam-se no final da década de 80 e inícios de 90, sobretudo em torno de temas como a globalização da TV, da desregulação e da privatização. Surge, neste período, o desenvolvimento dos canais privados que privilegiam conteúdos de âmbito nacional e internacional, influenciando a ação dos canais públicos no que concerne à sua atividade de âmbito regional e local, que se vê passada para segundo plano, e o fator proximidade perde relevância.

Nos anos 90, assistimos à digitalização dos meios de comunicação o que originou grandes mudanças no panorama audiovisual, especialmente com a diversificação e 
multiplicação de canais televisivos. Este contexto proporcionou o surgimento de novas experiências regionais e locais, como são os casos de cidades com os seus próprios canais e o reforço das estruturas regionais existentes. Na verdade, podemos dizer que a descentralização televisiva ocorreu na maioria dos países europeus, à exceção de Portugal e da Finlândia, onde os modelos centralizados continuam a resistir,

A diversidade de modelos de televisões regionais é evidente e reflete o nível de desenvolvimento social, político e económico das diferentes regiões europeias onde estão inseridas. Não obstante, vários investigadores apresentaram propostas de tipologias para esses modelos, dos quais destacamos as classificações tipológicas propostas por Pierre Musso (1991) e Garitaonandía (2000).

Para Musso (1991), existem cinco tipos de televisões regionais e locais: televisões regionais de cobertura nacional - SSR (Suíça) e RTBF (Bélgica); televisões regionais de cobertura regional - Canal 33 (Catalunha); televisões locais de cobertura regional; televisões nacionais com "janelas regionais" - FR3 (França), BBC (Reino Unido), TVE (Espanha), RAI3 (Itália) e televisões interregionais com "janelas regionais": ARD1 (Alemanha) e ITV (Reino Unido).

No estudo de Garitaonandía (2000), foram identificadas sete tipos de televisões regionais e locais: televisões de produção delegada na região - RTE (Irlanda), RTP (Portugal); televisões descentralizadas - RTVE (Espanha), FR3 (França), RAl3 (Itália); televisões de desconexão regional - BBC Escócia, France 3 Alsácia, TVE Catalunha; televisões de organização federada - televisões dos Länderalemães; televisões de gestão autónoma - televisões autonómicas de Espanha; televisões regionais de cobertura suprarregional, nacional e/ou internacional - RTBF e BRT (Bélgica) - e televisões locais de influência regional - TLT Télévision (Toulouse), Tele Norba (Itália) e IA Brandenburg (Alemanha).

Os avanços tecnológicos, mais concretamente a digitalização dos media, vieram alterar os conceitos tradicionais de difusão televisiva e as fronteiras geográficas foram destruídas com o surgimento da televisão por satélite, por cabo e através da internet. Daí que, mais do que falar de televisões regionais e locais, devamos falar de televisões de proximidade, "que produzem e emitem conteúdos de proximidade" e a existência de um "pacto de proximidade", partilhado com os destinatários desses conteúdos, que "descodificam a mensagem emitida" (Coelho, 2005: 171).

É aceite que a televisão exerce um papel central na promoção da coesão social e da construção da memória coletiva, daí que a existência de televisões comprometidas com os interesses e problemas das comunidades locais e regionais, não possa ser deixada para segundo plano. Contudo, essas televisões terão de estar adaptadas à dimensão sócio-económica da região onde estão inseridas, desenvolvendo a sua atividade em articulação com os demais setores que a compõem, num efetivo contributo para o desenvolvimento regional.

\section{O SERVIÇO PÚBLICO DE MEDIA: CONCEITOS E PERSPETIVAS}

A reflexão sobre o serviço público de rádio e televisão insere-se num campo de discussão muito mais extenso e que se inter-relaciona com outros domínios e contextos da sociedade contemporânea europeia. Contudo, e apesar dos inúmeros estudos que têm vindo a incidir sobre esta matéria, é de crucial importância continuar a investigar e a aprofundar o conhecimento sobre esta temática. 
Os desafios colocados ao serviço público são diversos, especialmente quando ele atravessa uma crise a três níveis: financeira, de identidade e de legitimidade, marcadamente fomentada pelo surgimento e desenvolvimento do digital e pela, cada vez maior, fragmentação e segmentação dos públicos. A solução passará pela reinvenção do seu papel estruturante na sociedade, que coloque o foco no cidadão, enquanto parceiro ativo neste processo, e que contribua para uma "relegitimação" do serviço público de media em Portugal (Cádima, 2012; Carvalho, 2009).

Sabemos que os media se afirmam no quotidiano como um dos principais mediadores, definidores e construtores sociais, transformando por completo o espaço público. Neste sentido, pensar e estudar o serviço público de rádio e televisão é essencial numa sociedade que se assume como democrática e tem no espaço público a sua maior força. (Berger \& Luckmann, 2010; Bourdieu, 1997; Esteves, 2003; Ferin, 2009; Schudson, 2003)

0 serviço público encerra em si responsabilidades sociais, assentes em princípios e valores que the são exigidos e que são o fundamento da sua essência e a sustentação da sua existência. Ao serviço público exigem-se princípios como a qualidade, a diversidade, a pluralidade, a representatividade, a neutralidade ou a independência. Ao centrar a sua prática na sociedade civil, deve ser capaz de promover a cidadania, favorecer a coesão social, valorizar a identidade coletiva, acoIher as diferentes realidades, contextos e expressões, garantir a qualidade e rigor informativo, estimular a criatividade e contribuir para o desenvolvimento regional. (Lopes, 1999; Pinto, 2005; Santos, 2013; Torres, 2011)

Para entender o conceito de serviço público, temos de recuar até ao séc. XIX, quando o belga César de Paepe afirma que o mesmo se reveste de um carácter de utilidade geral que uma determinada atividade desempenha na sociedade e que esse carácter deixaria de existir se essa atividade fosse desenvolvida por iniciativa privada.

A definição de serviço público constitui tema de debate no contexto do estudo das Ciências da Comunicação pois existem diversas correntes de pensamento sobre o seu papel e âmbito da sua missão.

Para autores como Cuilenburg e Slaa (1993), o serviço público deve centrar a sua atuação no campo informativo, deixando o entretenimento para os operadores comerciais. No plano oposto, estão autores como Collins (2010) e Torres (2011) que entendem que, mais do que estar circunscrito a um conjunto de operadores, 0 conceito de serviço público deveria ser alargado ao operadores privados e deveria evoluir para um "serviço público de conteúdos" (Torres, 2011: 104).

Uma outra perspetiva é a de Nissen (2006) e de Bardoel e D'Haenens (2008), que defendem que as novas tecnologias exerceram profundas transformações neste campo, pelo que já não será conveniente falar de serviço público de radiodifusão sendo que este deverá evoluir para um "serviço público de media", com a produção de novos géneros e formatos de programas, onde as potencialidades proporcionadas pelo meio digital possam ser exploradas de forma mais efetiva. Ainda nesta linha evolucionista, situamos Jakubowicz (2010) que defende a necessidade de um "serviço público de media em rede", isto é, onde um operador de serviço público, posicionado no "centro", seja capaz de articular uma rede de produção de conteúdos de interesse público que integre instituições e grupos da sociedade civil mas também operadores comerciais. 
Numa outra linha de pensamento, salientamos as posições de Blumler (1992, 1993), Born (2006), Cádima (2010) e losifidis (2007) que entendem que o serviço público deve ser promotor da diversidade cultural, do pluralismo político, da coesão social e da qualidade dos conteúdos. Para Blumler, o serviço público não pode centrar-se apenas na informação mas deve estender os seus princípios também ao entretenimento, como forma de conseguir desenvolver um verdadeiro serviço público, global e abrangente. Ele é bastante crítico relativamente a um modelo de financiamento que siga a lógica do mercado, pois considera que essa solução poderá condicionar a missão do serviço público. Também Born, considera que o serviço público deve relacionar-se com a comunidade onde se insere, numa relação de compromisso com os públicos, promovendo a diversidade cultural e o funcionamento saudável da democracia. Cádima (2011) defende que o serviço público é condição central no fortalecimento do projeto europeu e que a qualidade e a diversidade devem constituir a base do serviço público de radiodifusão, salvaguardando a promoção e valorização da diversidade cultural que caracteriza a realidade europeia. Já losifidis (2010), quando se refere às questões do pluralismo nos media de serviço público, é bastante crítico quanto à possibilidade de existirem vários operadores de serviço público num mesmo país, como garante desse pluralismo. Na verdade, 0 autor entende que o pluralismo deve existir sim, mas no seio de um único operador de serviço público e não pela existência de múltiplos operadores.

Vários autores, alguns dos quais já referidos, defendem que o serviço público deve ter como elemento central da sua missão o cidadão, isto é, deverá existir um compromisso e fidelidade para com o público, devendo satisfazer as suas necessidades e não limitar-se apenas às questões financeiras ou tecnológicas. Autores como Bardoel e D'Haenens (2008) defendem isso mesmo, a necessidade de assumir o público como parceiro no processo e não apenas para alcançar objetivos de natureza financeira. 0 cidadão deve ter um papel mais ativo e interventivo, que possa suscitar uma maior aproximação e identificação da sua parte com os média. Ainda neste sentido, Cádima $(2010,2011)$ entende que o serviço público deve ser garantia de acesso e presença da sociedade civil e promover espaços de participação cidadã, que possibilitem a participação de outras vozes no espaço público mediatizado. Ainda nesta linha de pensamento, devemos referir a posição de Fidalgo (2003) e Pinto (2003), para quem é um contrasenso a existência de um serviço público sem a presença e participação ativa do público.

Uma outra perspetiva é a que defende, de forma mais categórica, a necessidade de existir um serviço público que assente numa participação efetiva por parte do público na programação. Situamos nesta linha, a posições de Jakubowicz (2008, 2010) e Serrano (2010), que procuram dar resposta à realidade atual que se caracteriza pela convergência dos meios, a fragmentação dos públicos e a multiplicação de plataformas. Para o primeiro, o serviço público deve potenciar a participação do público inclusivamente na programação e nas decisões editoriais, bem como na definição de estratégias e que caminhos seguir. Para Serrano, podem existir experiências de uma colaboração mais abrangente entre operadores públicos e comerciais, desenvolvendo parcerias na produção de conteúdos com valor de serviço público.

Numa tentativa de definir o serviço público ideal, Eduardo Cintra Torres afirma que, mais do que servir a "máquina que o sustenta", o serviço público deve ser en- 
tendido como "serviço prestado à comunidade, no todo e nas partes, pelo custo estritamente necessário e sem substituir ou concorrer com serviços similares já disponíveis à mesma comunidade". (Torres, 2011: 83) 0 mesmo autor defende um serviço público centrado em conteúdos e na qualidade dos mesmos, "pois é isso que 0 cidadão vê e ouve" (ibidem, 87). Bastante crítico em relação ao atual modelo de serviço público nacional, este autor considera que o importante não é haver muitos canais e muitas horas de programação mas horas de boa programação e de conteúdos de qualidade.

Em 2011, foi criado pelo Governo um Grupo de Trabalho (GT) que tinha como objetivo a definição do conceito de serviço público de comunicação social, fazer uma análise do contexto atual e delinear estratégias para o futuro. 0 GT concluiu que só se deve "considerar como serviço público de comunicação social aquele e só aquele que cria e distribui à população conteúdos que contribuem para a formação das pessoas e para o seu enriquecimento cultural, impulsionados, estruturados e distribuídos sob supervisão pública e resultando de uma gestão racional e proporcionada dos recursos públicos." (GT, 2011: 10) Para tal, os prestadores de serviço público de comunicação devem concretizar os seguintes valores nos seus conteúdos: qualidade, diversidade, identidade cultural e autonomia financeira. Tal como foi defendido por Jakubowicz $(2008,2010)$ e Serrano $(2010)$, o carácter de serviço público dos conteúdos não deve estar monopolizado pelos operadores dos Estado, isto é, deve estender-se a outros operadores de conteúdos e até mesmo à sociedade civil, enquanto opção estratégica.

0 debate em torno deste conceito, apesar de complexo, continua a interessar os investigadores sobretudo no momento de transição em que vivemos. As tentativas e posições quanto à sua definição e missão, ao seu funcionamento e à sua sustentabilidade permanecem como campo de discussão. Na verdade, tendencialmente associado ao Estado, o serviço público confronta-se com a atribuição constante de uma forte carga ideológica relativamente ao seu papel na sociedade e o duplo sentido que reveste 0 entendimento sobre o mesmo. É frequente a confusão entre serviço público, enquanto organismo de produção do serviço, e serviço público, como missão de interesse geral confiado a esse organismo. É importante, pois, que esta discussão em torno dos conceitos se faça e seja repensada regularmente, acompanhando as novas tendências do mercado, das condições de receção, dos hábitos de consumo e das inovações tecnológicas.

\section{CONTEXTO PORTUGUES}

Comparativamente a outros países europeus, a realidade portuguesa, neste domínio, é bastante diferente, encontrando-se num grau de desenvolvimento claramente inferior. 0 contexto económico que caracteriza o setor audiovisual português, dependente das receitas provenientes da publicidade, dificultou a coexistência dos quatro canais televisivos e mesmo a rádio, que desempenhou um importante papel neste domínio, enfrenta atualmente problemas de financiamento e sustentabilidade.

Fortemente centralizado, o setor audiovisual em Portugal apresenta características bem diferentes dos restantes países europeus. A descentralização neste setor nunca foi uma prioridade para os sucessivos governos e, na verdade, esse facto dever-se-á quer à própria estrutura de governança portuguesa, que continua a centrar 
as ações e decisões na capital e não considera a regionalização como uma estratégia de desenvolvimento, quer às condições socioecónomicas das regiões menos desenvolvidas do país, considerando que existem outras prioridades de investimento.

No que respeita à televisão local em Portugal, podemos afirmar que existem duas fases: uma primeira, nas décadas de 70 e 80, onde são conhecidas algumas experiências de emissões ilegais, embora tenham sido silenciadas pelo Estado, e uma segunda, já na década de 90, quando surgem vários projetos clandestinos e 0 debate sobre esse assunto se torna mais consistente.

Desta segunda fase, destacamos o momento em que, na madrugada de 24 para 25 de abril de 1995, um grupo que se autodenomina TRP-Televisão Regional Portuguesa, realiza uma emissão televisiva ilegal que tinha como objetivo promover 0 debate em torno da possibilidade de criar uma rede de televisões regionais, alegando que, tal como tinha acontecido com as rádios locais, seria necessário criar um enquadramento legal que permitisse a existência de televisões locais. $\mathrm{Na}$ sequência desta emissão e da ação encabeçada pelo Movimento de Legalização das Televisões Locais, este assunto tornou-se tema de discussão pública e vários projetos de televisão regional ganhavam forma e exigiam uma nova legislação sobre a matéria, mostrando-se que estariam preparados para fazer emissões ilegais a qualquer momento e, assim, pressionar o Governo.

Relativamente a este assunto, num artigo de opinião, Arons de Carvalho afirmava de que a chegada de novos canais era "inevitável" e que deveria seguir o modelo aplicado à rádio. Certo é que, passados quase 20 anos, a situação permanece idêntica e, apesar de algumas experiências e tentativas, Portugal continua a não ter, no meio tradicional, televisões de âmbito local e regional.

Essa missão de produção de uma informação de proximidade tem vindo a ser desenvolvida pelos operadores existentes, quer em programas que se dedicam exclusivamente à informação regional, quer em programas generalistas que a incluem. Neste campo, devemos destacar o papel do operador público nacional que, ainda que com limitações, continua a ser pioneiro neste domínio e tem mostrado vontade e tomado medidas que procuram uma informação geograficamente descentralizada.

Em Portugal, o serviço público está concessionado à Rádio e Televisão S.A. mediante um contrato de concessão onde estão preconizados os direitos e as obrigações de ambos os outorgantes, Estado e Concessionária, com vista ao desenvolvimento deste serviço. Dele fazem parte diferentes serviços nos setores da televisão e da rádio, de atuação e abrangência nacional e internacional, com acesso livre e gratuito.

Estas obrigações materializam-se na assumpção de princípios orientadores que estruturam a oferta programática difundida e que são o garante da apresentação de uma programação "que promova a formaç̧ão cultural e cívica dos telespectadores, garantindo 0 acesso a todos à informação, à educação e ao entretenimento de qualidade."

Na verdade, o Contrato de Concessão acrescenta ainda que o Serviço Público deve constituir-se como um "fator de coesão e integração de todos os indivíduos, grupos e comunidades sociais", "assegurando a divulgação da diversidade da herança cultural nacional e europeia.", o que nos leva de novo à nossa problemática: como estão a ser representadas as diferentes regiões do país no serviço público português?

Relativamente a esta matéria, atualmente, a RTP possui os seguintes serviços e espaços dedicados à programação de âmbito regional: 
- dois serviços de programas destinados às regiões autónomas nacionais (RTP Açores e RTP Madeira)

- serviços generalistas com programas de carácter regional (Portugal em Direto);

- um centro de produção regional sediado no Porto (Centro de Produção do Norte);

- delegações regionais sediadas em algumas capitais de distrito (Bragança, Castelo Branco, Coimbra, Évora e Faro);

Contudo, estamos em condições de afirmar que ainda há muito por fazer no que respeita à descentralização da programação informativa no serviço público de comunicação social português.

Relativamente ao financiamento, e de acordo com o previsto no Contrato de Concessão, o Estado comparticipa nos custos dos serviços prestados, mediante um plano de financiamento plurianual e das receitas obtidas através da contribuição audiovisual, como compartida do cumprimento das obrigações contratualizadas.

Tendo como base os modelos teóricos de análise propostos por Hallin e Mancini (2010), o caso português insere-se no Modelo Pluralista Polarizado, que se caracteriza pelo desenvolvimento histórico tardio dos operadores comerciais, pela proximidade existente entre os media e o poder político, pelos reduzidos níveis de profissionalização no contexto jornalístico e pela presença centralizadora do Estado na sociedade portuguesa. De facto, os autores defendem que o Estado desempenha um papel bastante interventivo no sistema mediático português, nomeadamente nos setores da televisão e da rádio, ao que acresce o facto de ser também proprietário de uma agência noticiosa.

Esta intervenção revela-se a três níveis:

- concessão de apoios que procuram defender o Serviço Público dos concorrentes privados, sendo estes de natureza económica (contribuição do audiovisual e outros apoios) e técnica (cobertura);

- existência de um contrato de concessão que estabelece os deveres e obrigações que o Serviço Público deve cumprir como contrapartida dos apoios referidos;

- presença de estruturas de regulação e monitorização que garantem o cumprimento das obrigações.

Embora este modelo tenha apoio expresso por parte dos diferentes órgãos nacionais e europeus, ele não está imune a críticas sobre a sua atuação e a sua sustentabilidade. Algumas das críticas que lhe são feitas prendem-se com a sua indistinção face aos operadores privados, isto é, com uma visão estratégica orientada para o mercado e para as audiências, não cumprindo o seu papel de alternativa de qualidade relativamente aos concorrentes.

Conforme consta no Contrato de Concessão, o serviço público "deve constituir uma referência para a população" e apresentar uma programação "globalmente diferenciadora face à oferta do mercado audiovisual português".

No entanto, um estudo realizado pela ERC em 2008, sobre a receção dos meios de comunicação social, demonstrou que a informação da televisão pública é considerada pelos portugueses como a mais credível. No entanto, o Relatório da Regulação produzido pela mesma entidade em 2015 revelou que a televisão pública 
não se distingue das suas concorrentes privadas ao nível dos conteúdos difundidos. Embora Ihe seja reconhecida credibilidade, aquilo que se verifica é um considerável mimetismo entre o canal público e os privados nas abordagens, enfoques, temas, atores e fontes selecionados, o que coloca em causa a sua ação em matérias de proximidade, diversidade, qualidade e pluralismo.

\section{NotAs FinAIS}

A cobertura das diferentes regiões nacionais é uma obrigação do serviço público. Ora, num país que se caracteriza por acentuadas assimetrias regionais, evidentes em quase todos os domínios da vida pública, entendemos ser crucial analisar qual o papel do serviço público de rádio e televisão neste processo.

Sabemos que estes conteúdos informativos encerram representações e interpretações da realidade social e que, ao colocarem na agenda pública aquilo que é merecedor de relevância mediática, contribuem, em larga medida, para aquilo que será discutido na esfera pública. Sabemos também que a informação de âmbito local e regional assume diversas funções na sociedade e que a descentralização dos meios de comunicação deve ser encarada como um dos eixos do serviço público e, mais que uma intenção, deve refletir-se na programação diária do operador público.

Esta temática relaciona-se com outros aspetos que caracterizam a missão do serviço público de media e que urgem ser estudados, na tentativa de identificar não só os problemas que este encerra mas também de encontrar soluções que viabilizem a sua continuidade, enquanto pilar das sociedades democráticas. Entre eles, destacamos as questões que se referem à diversidade, ao pluralismo e à proximidade da informaç̧ão no serviço público de comunicação.

A temática em torno do conceito da diversidade e do pluralismo nos meios de comunicação necessita urgentemente ser estudada e posteriormente avaliada à luz da crescente globalização dos conteúdos audiovisuais. E esta questão é um tema que tem vindo a interessar quer investigadores quer reguladores pois, no geral, ambos consideram que estamos a assistir a uma crescente uniformização e homogeneização da programação nos meios de comunicação e que existe uma desequilibrada representatividade de determinados grupos ou elementos da sociedade nos meios de comunicação social, como são os casos das mulheres, das minorias étnicas e/ ou raciais, das pessoas com deficiência, dos idosos e dos jovens.

Esta realidade é bastante evidente tanto a nível nacional como também a nível europeu, daí que a estratégia Europa 2020 dê especial destaque às questões da diversidade e do pluralismo, no sentido de que os meios audiovisuais contribuam para o combate a todas as formas de discriminação e exclusão social, para a promoção da tolerância e da multiculturalidade e para o fomento coesão social.

É sabido que uma das obrigações do serviço público de media é a promoção da diversidade cultural e do pluralismo, integrando de igual forma e representando todos os segmentos da população. Como se pode ler no Contrato de Concessão do Serviço Público de Rádio e Televisão, este está incumbido de "fornecer uma programação variada, diferenciadora e abrangente, que promova a diversidade cultural e tenha em conta os interesses das minorias" bem como de "promover o acesso público às manifestações culturais portuguesas e garantir a sua cobertura informativa adequada". 0 mesmo documento refere ainda que "os diferentes serviços de 
programas devem refletir a diversidade do país" e coloca nos diferentes centros de produção regionais a responsabilidade da produção desses conteúdos.

É evidente que existe uma preocupação com estas matérias, nomeadamente uma especial atenção para a representação das distintas realidades territoriais e dos diferentes grupos constitutivos da realidade portuguesa. Contudo, nem sempre aquilo que está preconizado em documentos escritos se aplica na prática pelo que é fundamental continuar a aprofundar e desenvolver estudos neste campo, de forma a comprovar cientificamente se estas obrigações estão ou não a ser cumpridas.

Falar de proximidade no jornalismo numa sociedade que revela, cada vez mais, as dimensões atribuídas ao fenómeno da globalização, é, hoje, essencial. Os discursos sobre proximidade têm vindo a ganhar um nova importância ao nível da sociedade em geral e assistimos a uma redescoberta do papel do "local". Cada vez mais vemos surgirem movimentos e tomadas de posição que colocam a tónica na importância do "local" enquanto fator diferenciador e identitário, bem como na necessidade de encetar políticas de proximidade e de maior ligação ao contexto que lhe é mais próximo.

No que respeita ao jornalismo, o critério da proximidade é um dos mais valorizados pelos jornalistas e constitui um dos valores-notícia centrais, como é defendido pelos diversos investigadores quando abordam esta questão. 0 critério da proximidade está relacionado com o interesse do público pelos acontecimentos próximos a ele e com os quais existe uma identificação social, respondendo positivamente a notícias que possuam essas características.

$\mathrm{Na}$ verdade, a proximidade é um elemento determinante aquando da procura da informação e da seleção de notícias porque se considera que "as pessoas estão interessadas em saber o que acontece nos arredores, nas proximidades, no seu entorno e não só geográfico, mas também o social e psicológico." (Fontcuberta, 2010).

Contudo, esta característica não é exclusiva dos órgãos regionais e locais mas é transversal a todas as formas de jornalismo, pois relaciona-se com a necessidade de comunicar informação considerada relevante para os públicos e sabe-se que desenvolver a relevância junto das audiências através da proximidade é uma das formas de gerar atenção junto das mesmas. Como refere Camponez (2002), a proximidade torna o jornalismo "mais humano e mais verdadeiramente social", promovendo a sociabilidade e o sentimento de pertença e contribuindo para um fortalecimento da relação que existe entre os meios de comunicação e os cidadãos.

A informação de proximidade, porque se centra na informação âmbito local, permite criar e manter laços entre os meios de comunicação e os públicos porque ela é insubstituível e crucial na "aldeia global" que se tornou o nosso mundo. Ela expressa as especificidades de uma determinada comunidade, chega onde a outra informação, a nacional, não chega, aborda e traz para o espaço público os problemas e as aspirações reais das pessoas.

Na verdade, a proximidade contribui para a criação de "espaços alternativos de comunicação" (Coelho, 2005: 154) e acentua o papel crucial desempenhado pelo jornalismo de proximidade no respeito pelo pluralismo, na promoção da tolerância e no reforço da coesão social.

Como defende Wolton, há que "destecnificar a comunicação", há que "humanizá-la e socializá-la" (1999: 176) e isso é possível com a afirmação de um jornalismo que tenha na proximidade um dos seus pilares. 
Um dos grandes desafios que hoje o serviço público enfrenta é conseguir conciliar as pressões do mercado com uma programação diversificada e de qualidade, próxima dos cidadãos, capaz de manter o seu carácter diferenciador e a sua legitimidade. Neste complexo processo, a valorização da diversidade e da proximidade são eixos fundamentais na medida em que todas as vozes e expressões culturais integram o nosso património e fazem parte da nossa identidade e refletem o mundo plural em que vivemos. Ao centrar a sua prática na sociedade civil, que se revê nos meios de comunicação, o serviço público deve ser capaz de promover a cidadania, favorecer a coesão social, valorizar a identidade coletiva, acolher as diferentes realidades, contextos e expressões, garantir a qualidade e rigor informativo, estimular a criatividade e contribuir para o desenvolvimento.

\section{REFERÊNCIAS BIBLIOGRÁFICAS}

Abbot, S. (2016). Rethinking Public Service Broadcasting's Place in International Media Development. Center for International Media Assistance (CIMA). Disponível em http:// www.cima.ned.org/wpcontent/uploads/2016/02/CIMA_2016_Public_Service_Broadcasting.pd

Appadurai, A. (2004). Dimensões Culturais da Globalização. Lisboa: Teorema.

Areal, M. F. (1997). El Público en los medios locales de comunicación. Estudios de Periodística. Pontevedra: Diputación de Pontevedra. pp. 21-43.

Badie, B. (1996). O Fim dos Territórios - Ensaio sobre a desordem internacional e sobre a utilidade social do respeito. Lisboa: Instituto Piaget.

Bardoel, J; d'Haenens, L. (2008). Reinventing public service broadcasting in Europe: prospects, promises and problems. Media Culture Society 30.

Berger, P. \& Luckmann, T. (2010). A construção social da realidade (3. ${ }^{a}$ edição). Lisboa: Dinalivro. (Original publicado em 1966).

Blumler, J. (ed) (1992). Television and the Public Interest. London: Sage Publications.

Bourdieu, P. (1997) Sobre a Televisão. Oeiras: Celta Editores.

Brandão, N. G. (2010). As Notícias nos Telejornais - Que serviço público para o século XXI? Lisboa: Guerra e Paz.

Cádima, F. Rui (2012). A Relegitimação do Serviço Público de Televisão em Portugal no contexto de hiperfragmentação da oferta. In Anuário Internacional de Comunicação Lusófona, 10. Santiago de Compostela: AGACOM e LUSOCOM, pp. 25-33.

Cádima, F. Rui. \& Faustino, P. (2013). Políticas Públicas, Media e Estado. Lisboa: Formalpress/Media XXI.

Camponez, C. (2002). Jornalismo de Proximidade - Rituais de Comunicação na imprensa Regional. Coimbra: Minerva.

Carvalho, A. A. (2009). A RTP e o Serviço Público de Televisão. Coimbra: Almedina.

Coelho, P. (2005). A TV de proximidade e os novos desafios do espaço público. Lisboa: Livros Horizonte.

Donnelly, L. (2005). Proximity, not story format, improves news awareness among readers. Newspaper Research Journal 26: 59-65.

Duarte, F. (2005). Informação de Proximidade. Lisboa: Âncora Editora. 
Esteves, J. P. (2003). Espaço Público e Democracia. Lisboa: Edições Colibri.

Faist, T. (2008). Diversity - a New Mode of Incorporation?. Ethnic and Racial Studies 32 (1): 171-190.

Fontcuberta, M. de (2010). A notícia. Pistas para compreender o mundo (3. ${ }^{a}$ edição). Alfragide: Casa das Letras/Oficina do Livro.

Giddens, A. (1997). Modernidade e Identidade Pessoal. Oeiras: Celta Editora.

Gomis, L. (1991). Teoria del periodismo. Como se forma el presente. Barcelona: Paidós.

Hallin, D. \& Mancini, P. (2004). Comparing Media Systems. Three models of media and politics. Cambridge: Cambridge University Press.

Horsti, K.; Hultén, G; Titley, G. (2014). National Conversations: Public Service Media and Cultural Diversity in Europe. Intellect Books.

Huxford, J. (2007). The proximity paradox: Live reporting, virtual proximity and the concept of place in news. Journalism, 8(6): 657-674.

Jakubowicz, K. (2011). Serviço público na Europa. O princípio do fim ou um novo começo no século XXI?. Instituto Politécnico de Lisboa. (http://repositorio.ipl.pt/bitstream/10400.21/1868/1/cap01.pdf).

Lopes, F. (1999a). O Telejornal e o Serviço Público. Coimbra: Minerva.

Lopes, F. (1999b). As Notícias Regionais no telejornal da RTP: que serviço público?. Comunicação e Sociedade, Cadernos do Noroeste, Série Comunicação 12 (1-2): 131-150.

Lowe, G. F. \& Martin, F. (eds.) (2013). The Value of Public Service Media. Göteborg: Nordicom. Mabileau, A. (1989). L'Information Locale. Paris: Pedone.

Martin, S. N. (1988). Proximity of event as factor in selection of news sources. Journalism Quarterly 65(4): 986-1043.

Mathien, M. (1993). La Presse Quotidienne Régionale. Paris: PUF. $3^{\text {a }}$ ed

Mesquita, M. (2003). o Quarto Equívoco - o poder dos media na sociedade contemporânea. Coimbra: Minerva Editora.

Moragas Spà, M. et. al. (1999). Televisión de proximidad en Europa: experiencias de descentralización en la era digital. Barcelona.

Musso, P. (1991). Régions d'Europe et Télévision. Editions Miroirs.

Neveu, E. (2002). The local press and farmers' protests in Brittany: Proximity and distance in the local newspaper coverage of a social movement. Journalism Studies. 3(1): 53-67.

Nissen, C. (2006). Public Service Media in the Information society, Strasbourg, Council of Europe. Disponível em http://www.coe.int/t/dghl/standardsetting/media/doc/HInf(2006)003_en.pdf

Ofcom. (2009). Local and Regional Media in the UK. Disponível em http://stakeholders.ofcom.org.uk/binaries/research/tv-research/lrmuk.pdf

Pinto, M. (Org.) (2005). Televisão e Cidadania. Contributos para o Debate sobre o Serviço Público. Porto: Campo das Letras.

Recommendation Rec (2007)3 of the Committee of Ministers to member states on the remit of public service media in the information society, 31 January 2007, Preamble.

Ringlet, G. (1981). Le Mythe au Milieu du Village - Comprendre et analyser la presse locale. Bruxelas: Vie Ouvrière.

Santos, S. C. (2013). Os Media de Serviço Público. Covilhã: Labcom 
Shoemaker, P. . (2007). Proximity and Scope as News Values. Media Studies - Key Issues and Debates. Londres: Sage. pp. 231 - 248.

The importance of regional public service media. A strategic view of the role of regional public media in Europe. CIRCOM Regional. 2014. Disponível em http://www.circom-regional. eu/doc-download/cr-docs/1406-circom-regional-position-paper/file

Torres, E. C. (2011). A Televisão e o Serviço Público. Lisboa: Fundação Francisco Manuel dos Santos.

Wolton, D. (1999). Pensar a Comunicação. Algés: Difel.

Patrícia Ascensão - Doutoranda do curso de Ciências da Comunicação da FCSH/NOVA. Investigadora colaboradora do CIC.Digital (Pólo FCSH/NOVA).

Data de recepção do artigo/ Received for publication: 15.03.2017

Data de aceitação do artigo/ Accepted in revised form: 01.05.2017 